This observation motivated neuroscientist Rodolfo Llinás, in his 2002 book I of the Vortex, to propose that, at bottom, thinking is the evolutionary internalization of movement. He meant that thinking is the generation in the brain of images of a future action, and its consequences. And generating these images depends on flexibility in categorizing the current problem as an instance of one kind of event rather than another, which, in turn, depends on memory for past experience. Fundamentally, thinking is neural activity in the service of behaviour (for example, should I flee or fight? Is this attacker weak or strong?). This almost certainly shapes thinking that seems detached from motor preparation (such as, where did Earth come from?).

As is so often the case in biology, discover- ing structure is crucial in coming to understand function - as in William Harvey's seventeenth-century revelation that hearts are actually pumps, not biological cauldrons for concocting animal spirits. To figure out how brains actually think and what reasoning really amounts to, we need to focus on understanding their many levels of organization, from neurons to large-scale systems to behaviour. If thinking is rooted in internalized movement, it may be more akin to a skill than to a syllogism. Language may not be the "stuff of thought" after all

Patricia S. Churchland is professor of philosophy at the University of California San Diego, La Jolla, California 92093, USA. She is the author of BrainWise: Studies in Neurophilosophy.

\title{
Prions, pleasure and purple notes
}

\section{Proust was a Neuroscientist \\ by Jonah Lehrer \\ Houghton Mifflin: 2007. 256 pp. \$24 \\ The Hidden Sense: Synesthesia in Art and Science \\ by Cretien van Campen \\ MIT Press: 2007.208 pp. $\$ 29.95$}

\section{Chris McManus}

"Oh no he wasn't!" might well be the response to Jonah Lehrer's claim that Proust was a neuroscientist. And neither were Walt Whitman, George Eliot, Auguste Escoffier, Paul Cézanne, Igor Stravinsky, Gertrude Stein or Virginia Woolf. For Lehrer, an editor on the science and culture glossy Seed, neuroscience has confirmed their artistic intuitions: "Proust was right about memory, Cézanne was uncannily accurate about the visual cortex, Stein anticipated Noam Chomsky, and Woolf pierced the mystery of consciousness."

Lehrer's conceit of the artist as a neuroscientist is not unique. Neurobiologist Semir Zeki feels Shakespeare and Wagner are "among the greatest of neurologists", probing the mind of man using language and music. Likewise, cognitive psychologist Patrick Cavanagh has written of painters whose use of shadows, colours, reflections and contours shows how the "visual brain uses a simpler, reduced physics", and hence that "artists act as research neuroscientists".

Call me old-fashioned, but neuroscience surely needs at least some indirect involvement with the greyish-pink stuff inside heads? However valid in their own way, painting, cooking, and writing novels, poems and music simply aren't neuroscience. Even cognitive science would be pushing it. Where are the methodology, the experimentation, the data and the hypothesis testing? "The impression is for the writer what experimentation is for the scientist," said Proust. But impressions are neither experiments nor science. The conceit remains exactly that, if the term 'neuroscientist' is to retain any serious meaning.

The Proust chapter in Lehrer's elegant book includes some brief biographical background, a little on Henri Bergson's influence, and then the famous passage with the madeleine: "What did Proust learn from these prophetic crumbs of sugar, flour, and butter? He actually intuited a lot about the structure of our brain." These intuitions included "smell and taste are the only senses that connect directly to the hippocampus, the center of the brain's long-term memory, [whereas] all other senses are first processed by the thalamus, the source of language and the front door to consciousness". If indeed Proust intuited this anatomy, it was unfortunate because the taste pathway is wrong, and few regard the thalamus as the source of language - particularly Proust's compatriot, Paul Broca.

Neuroscientists are then painted as naïve and uncultured, assuming that memories are "just shelved away in the brain, like dusty old books in a library" and that the secret of memory lies in "senseless repetition". After a ramble through Cajal and Freud, and a rat experiment on remembrance and reconsolidation, comes a deep dive into neurobiologist Kausik Si's ideas on the prion-like cytoplasmic protein CPEB. This protein, Si believes, may participate in the formation of long-term memory, and in some way explains how Combray, the fictional village of Proust's childhood, could exist "silently below the surface, just behind the curtain of consciousness". Lehrer triumphantly concludes that "prions are, by definition, unpredictable and unstable, because memory obeys nothing but itself. This is what Proust knew: the past is never past".

The most interesting parts of Proust was a Neuroscientist are its manifestos on art and science in the prelude and coda. Lehrer accuses scientists of seeing the brain solely in terms of its physical details, as "nothing but a loom of electrical cells and synaptic spaces", and of forgetting that "this isn't how we experience the world". Some scientists maybe, but it hardly describes psychologists. The coda begins with the "incommensurate languages" of C. P. Snow's The Two Cultures, and then attacks Richard Dawkins, Brian Greene, Steven Pinker and E. O. Wilson and the "third culture" for being antagonistic towards everything nonscientific and lacking a dialogue of equals.

By contrast, Ian McEwan's Saturday is invoked as a rare cultural commodity that possibly symbolizes the birth of a new fourth culture, in which the humanities engage sincerely with the sciences. Lehrer argues that every humanist should read Nature and that scientists should recognize truths other than their own, with art "a necessary counterbalance to the glories and excesses of scientific reductionism, especially as they are applied to human experience". It's a grand dream but, for me, Lehrer's own attempt at a fourth culture fails. As Gerard Manley Hopkins might say, whatever "the achieve of, the mastery of" the artists, the science as laid out here seems "sheer plod", undermining the central conceit - for what artist would partake in such a paltry matter?

Lehrer's last lines posit that the individuality of our experiences is what science will never be able to serve, because "each of us literally inhabits a different brain, tuned to the tenor of our private desires". I was therefore surprised to find no mention of synaesthesia, whose recent scientific renaissance confronts the idiosyncratic perceptions described by artists such as Wassily Kandinsky, Alexander Scriabin and Vladimir Nabokov, and which potentially provides a fertile middle ground between art and science.

In The Hidden Sense, Cretien van Campen, a self-styled naturalist of synaesthesia, explores this ground, providing a gentle, insightful, often personal, account of coloured words, smells, tones, pains, even orgasms, that will fascinate scientists, artists, synaesthetes and others. Slowly, this deep, seemingly intractable, subjectivity yields to some phenomenology, simple questionnaires, elegant experiments, a dash of neuroimaging, and much thought and reflection.

Synaesthesia is not, says van Campen, "an audiovisual performance, a trend in art or music, a drug-induced hallucination, a kind of metaphor". Nor is it, he concludes, a rare, demarcated, distinctive anomaly like colourblindness. Synaesthesia is instead the end of a continuum, manifesting as intermediate forms in most people. He classes synaesthesia within Kant's sensus communis aestheticus, emphasizing the pleasure, joy and "hypnotising beauty" of the phenomena experienced.

Chris McManus is professor of psychology and medical education in the Division of Psychology and Language Sciences at University College London, London WC1E 6BT, UK. His book Right Hand, Left Hand won the 2002 Aventis Prize for Science Books. 